\title{
Minimally invasive procedures in severe acute pancreatitis treatment - assessment of benefits and possibilities of use
}

\author{
Jacek Szeliga, Marek Jackowski \\ Department of General, Gastroenterological and Oncological Surgery, Collegium Medicum Nicolaus Copernicus University, Torun, Poland
}

Videosurgery Miniinv 2014; 9 (2): 170-178

DOI: $10.5114 /$ wiitm.2014.41628

\begin{abstract}
Introduction: Acute pancreatitis (AP) consists of an extremely varied complex of pathological symptoms and clinical conditions, ranging from mild gastric complaints to multi-organ failure resulting in death.

Aim: To present the authors' own experience regarding surgical treatment for pancreatic necrosis complicated by infection using different methods, including classic and laparoscopic methods as well as those combined with percutaneous techniques.

Material and methods: In the period 2007-2010, 34 patients with the diagnosis of severe AP were treated at the Department of General, Gastroenterological and Oncological Surgery, Collegium Medicum, Nicolaus Copernicus University. In 7 patients classic necrosectomy with repeated peritoneal flushing was performed (type 1), in 5 patients laparotomy with active drainage (type 2), in 12 video-assisted retroperitoneal debridement (type 3), and in 10 only percutaneous drainage methods (type 4).

Results: Total duration of hospitalisation was from 10 to 192 days. The highest death rate was observed for type 1 procedures. Significant differences with regard to the absolute number of postoperative complications between different groups were not observed; however, their quality varied. Classic methods were used in patients whose general and local condition was more severe.

Conclusions: When AP and its complications are diagnosed, a suitable method of surgical treatment has to be selected extremely precisely and in an individualised way. Minimally invasive methods used in selected patients provide better outcomes and higher safety superseding classic, open techniques of surgical treatment.
\end{abstract}

Key words: acute pancreatitis, infected pancreatic necrosis, video-assisted retroperitoneal debridement.

\section{Introduction}

Acute pancreatitis (AP) consists of an extremely varied complex of pathological symptoms and clinical conditions, ranging from mild gastric complaints to multi-organ failure resulting in death. The mortality associated with this disease is estimated to reach $5 \%$. Unfortunately in the case of severe symptoms of AP that develop in $20 \%$ of patients on average, the risk of treatment failure increases even up to $47 \%[1,2]$. A similar failure rate (even $50 \%$ ) is observed for sur- gical treatment itself introduced when infected necrosis has been diagnosed [3].

Treatment of mild AP is not under much debate; nonetheless, no algorithms that could be used in a satisfactory way have been developed so far for patients with a severe form of this disease. In this case treatment of AP complications such as organ failure is quite well known, but the problem is associated with preparing an individual management strategy for local complications in the area of the pancreas itself. Surgical treatment including different types 
of necrosectomy performed laparoscopically is not perfect; therefore recently more and more often attempts to use minimally invasive procedures have been undertaken.

\section{Aim}

This paper presents the authors' own experience regarding surgical treatment of pancreatic necrosis complicated by infection using different methods, including laparoscopic ones and those combined with percutaneous techniques (video-assisted retroperitoneal debridement - VARD).

\section{Material and methods}

In the period 2007-2010, 34 patients with the diagnosis of severe AP based on the Atlanta criteria were treated at the Department of General, Gastroenterological and Oncological Surgery, Collegium Medicum, Nicolaus Copernicus University, Torun. Table I presents characteristics of patients.

The patients were treated according to the AP therapeutic standards from the very beginning. Antibiotic therapy was not used as prophylaxis due to AP itself. Probe enteral nutrition was used when peristalsis was present. When enteral nutrition was not tolerated total parenteral nutrition was introduced.

Table I. Characteristics of the studied group of patients

\begin{tabular}{|lc|}
\hline Characteristic & Results, $n$ (\%) \\
\hline Gender: & $21(62)$ \\
\hline$M$ & $13(38)$ \\
\hline Age, mean $(\mathrm{range})[$ years] & $28-78(52)$ \\
\hline BMI, mean $\left[\mathrm{kg} / \mathrm{m}^{2}\right]$ & 29 \\
\hline Aetiology: & $14(41)$ \\
\hline Biliary & $18(53)$ \\
\hline Alcohol & $2(6)$ \\
\hline Other & $14(41)$ \\
\hline Transfer from another centre & 29 \\
\hline Ranson score: & 5 \\
\hline$\leq 3$ & 0 \\
\hline $4-6$ & \\
\hline 7 & \\
\hline
\end{tabular}

The patients' condition was monitored according to the APACHE II score and the radiological criteria (Balthazar scale - computed tomography severity index (CTSI) index) (Table II).

A post-inflammatory, infected focus or foci within the pancreas and/or peripancreatic region was diagnosed in all analysed patients. The diagnosis of necrosis infection was based not only on typical clinical symptoms, but also on the computed tomography (CT) result and, in 27 cases, results of a microbiology examination.

When the diagnosis of infection was made, targeted antibiotic therapy was started and the patient's condition was monitored. When the clinical status deteriorated and signs of sepsis progressed, a decision was made to perform a surgical intervention. In this group of patients 4 types of procedures (INTERV) were performed and they are presented Table III. A decision regarding the type of surgery was made based on the patient's general condition. In the first stage of the analysed period when laparoscopic experience did not provide sufficient safety to patients, decisions to perform laparoscopic procedures were mainly made, whereas in the second period minimally invasive procedures were preferred.

Finally, type 1 procedures were considered appropriate for 7 patients in whom clinical symptoms of progressive sepsis were predominant; the patient's condition deteriorated despite intensive treatment, and $\mathrm{X}$-ray and fine needle aspiration examinations confirmed signs of infection of organ necrosis. In this case decisions regarding surgical treatment were made relatively early, namely on day 17 after the first symptoms had developed. In view of the fact that at this disease stage it is extremely difficult to remove ischaemic and necrotic tissue in the peripancreatic area (as they are not completely demarcated yet) a decision was made to introduce treatment including scheduled relaparotomies repeated every 2 days on average and passive drainage. Type 2 procedures which are currently recom-

Table II. Distribution of maximum CTSI indices in the studied group

\begin{tabular}{|cc|}
\hline CTSI & No. \\
\hline 7 & 3 \\
\hline 8 & 17 \\
\hline 9 & 10 \\
\hline 10 & 4 \\
\hline
\end{tabular}


Table III. Basic data regarding procedures performed in the analysed group

\begin{tabular}{|lcccc|}
\hline Type & Procedure (INTERV) & No. & $\begin{array}{c}\text { Confirmed infection } \\
\text { (extrapancreatic indications) }\end{array}$ & $\begin{array}{c}\text { Intervention } \\
\text { day }\end{array}$ \\
\hline 1 & $\begin{array}{c}\text { Laparotomy + necrosectomy + passive } \\
\text { drainage (scheduled repeated laparotomies) }\end{array}$ & 7 & $5(2)$ & 17 \\
\hline 2 & $\begin{array}{r}\text { Laparotomy + necrosectomy + } \\
\text { active drainage }\end{array}$ & 5 & $5(0)$ & 23 \\
\hline 3 & Percutaneous drainage + VARD & 12 & $12(0)$ & 33 \\
\hline 4 & Percutaneous drainage & 10 & $10(0)$ & 29 \\
\hline
\end{tabular}

mended were performed for such indications when the patient's clinical condition was satisfactory until at least 3 complete weeks of disease had passed. Then as early as during the first intervention more necrotic tissue was removed from the pancreas, and the remainder was flushed out via active drainage of the peripancreatic area. Type 3 procedures were considered appropriate for patients in whom an attempt of percutaneous drainage to collect fluid or foci of pancreatic necrosis had been made, but no satisfactory clinical outcomes were observed after such a procedure. In general lack of effects indicated no improvement of the clinical condition within

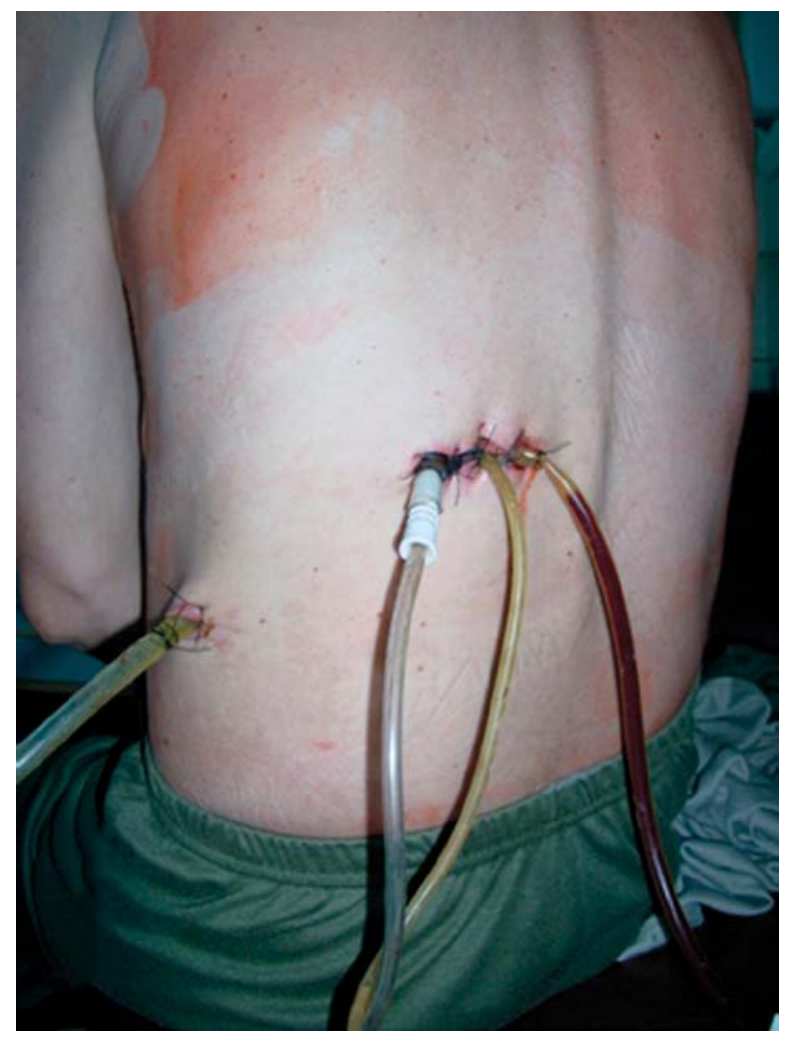

Photo 1. Flushing drainage after VARD the next $48-72 \mathrm{~h}$ and further sepsis progression, or there were too extensive necrotic lesions combined with relative inefficacy of drain(s) (1 or 2) placed, namely the infected contents were not released. Then, during the second stage VARD was performed. Finally, type 4 procedures were considered suitable for patients who received only percutaneous drainage (12 to $20 \mathrm{~F}$ drains) of necrotic and suppurative cisterns from the pancreatic area. This group had the lowest APACHE II score and included patients in the best general condition. Their surgical treatment for AP ended with this procedure.

\section{Video-assisted retroperitoneal debridement}

The authors' own procedure technique was prepared based on techniques described in the PANTER trial $[4,5]$. An approx. 5-cm incision in the left lumbar area was made at the site of a drain to be introduced, or after determination during an ultrasound examination so that it would not interfere with significant anatomical structures (such as large vessels) and would be at the lowest distance in relation to the target space indicated for drainage. After integuments were dissected, the peripancreatic space was reached bluntly, most frequently with a finger and under ultrasound supervision, so as to achieve free flow of infected, necrotic tissues. Then a laparoscopic camera was introduced and under video supervision necrotic tissues were flushed out using a suction-flushing device. No attempt was undertaken to remove fragments of necrotic pancreas that were not demarcated; they were left for subsequently placed active, flushing gravitational drainage covering the bed after necrosectomy, and including a reception drain of 24-28 F and 1-3 $16 \mathrm{~F}$ drains used to administer saline or Ringer solution (Photo 1).

After the procedure the patient was supervised at the ICU, having basic vital signs monitored, with 

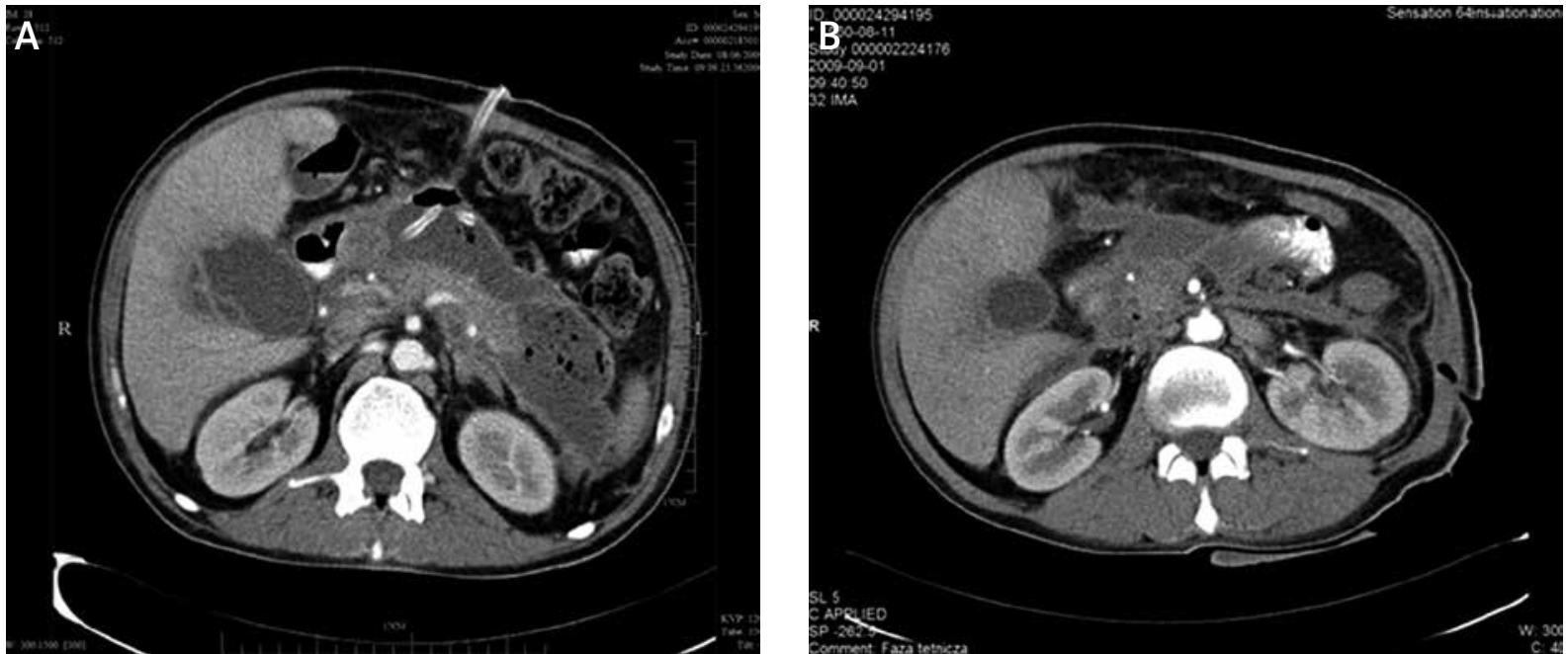

Photo 2. Sample tomograms of the abdominal cavity of a patient who had percutaneous drainage placed (A) and after VARD (B)

compensated nutrition and water-electrolyte balance. The clinical condition improvement was evaluated (APACHE II) as well as evolution of changes in the pancreatic area using CT (Photos $2 \mathrm{~A}$ and $2 \mathrm{~B}$ ).

\section{Results}

In the period 01.2006 to $12.2010,34$ patients diagnosed with severe AP were treated at the department. Total duration of hospitalisation was from 10 to 192 days (median: 62). Depending on how a local condition was defined in imaging tests procedures presented in Table IV were performed in patients.

The most serious complication was patient's death and it was observed in all groups (Table V). The most common cause of fatal complications included multiorgan failure due to sepsis. When analysing surgical perioperative complications only those that were a result of surgery performed earlier were referred to (Table VI).

As can be observed, in almost half, namely in as many as $44 \%$ of surgically treated patients different types of infection complications were observed in wounds (Table VI). This problem was observed only in 1 patient who received percutaneous drainage of the peripancreatic area. However, unfortunately in the latter group there was a serious complication, i.e. iatrogenic damage to the colon in the area of the splenic flexure. This patient died 3 weeks later as

Table IV. Types of procedures depending on the CTSI index

\begin{tabular}{|c|c|c|c|}
\hline Type & CTSI index & Procedure & No. \\
\hline \multirow[t]{2}{*}{1} & 10 & Laparotomy + necrosectomy + passive drainage (scheduled repeated laparotomies) & 5 \\
\hline & 9 & & 2 \\
\hline \multirow[t]{2}{*}{2} & 10 & Laparotomy + necrosectomy + active drainage & 2 \\
\hline & 9 & & 3 \\
\hline \multirow[t]{3}{*}{3} & 9 & Percutaneous drainage + VARD & 3 \\
\hline & 8 & & 8 \\
\hline & 7 & & 1 \\
\hline \multirow[t]{3}{*}{4} & 9 & Percutaneous drainage & 1 \\
\hline & 8 & & 6 \\
\hline & 7 & & 3 \\
\hline
\end{tabular}


Table V. Perioperative complications, including deaths, after individual procedures performed

\begin{tabular}{|c|c|c|c|c|}
\hline Type & Procedure & No. & $\begin{array}{l}\text { No. of patients with perioperative } \\
\text { complications, } n(\%)\end{array}$ & $\begin{array}{l}\text { Death, } \\
n(\%)\end{array}$ \\
\hline 1 & $\begin{array}{l}\text { Laparotomy + necrosectomy + passive drainage } \\
\text { (scheduled repeated laparotomies) }\end{array}$ & 7 & $7(100)$ & $5(71.4)$ \\
\hline 2 & Laparotomy + necrosectomy + active drainage & 5 & $5(100)$ & $1(20.0)$ \\
\hline 3 & Percutaneous drainage + VARD & 12 & $6(50)$ & $2(16.6)$ \\
\hline 4 & Percutaneous drainage & 10 & $2(20)$ & $1(10.0)$ \\
\hline
\end{tabular}

Table VI. Types of complications depending on procedure type

\begin{tabular}{|c|c|c|c|}
\hline Type & Complication & No. & $\begin{array}{l}\text { Percentage of perioperative } \\
\text { complications }\end{array}$ \\
\hline \multirow[t]{4}{*}{1} & Wound infection & 3 & 42.8 \\
\hline & Haemorrhage at a surgical site & 2 & 28.6 \\
\hline & Pancreatic fistula & 2 & 28.6 \\
\hline & Intestinal fistula & 1 & 14.3 \\
\hline \multirow[t]{4}{*}{2} & Wound infection & 4 & 80.0 \\
\hline & Haemorrhage at a surgical site & 0 & 0.0 \\
\hline & Pancreatic fistula & 2 & 40.0 \\
\hline & Intestinal fistula & 0 & 0.0 \\
\hline \multirow[t]{4}{*}{3} & Wound infection & 4 & 30.0 \\
\hline & Haemorrhage at a surgical site & 1 & 8.3 \\
\hline & Pancreatic fistula & 2 & 16.6 \\
\hline & Intestinal fistula & 0 & 0.0 \\
\hline \multirow[t]{4}{*}{4} & Wound infection & 1 & 8.3 \\
\hline & Haemorrhage at a surgical site & 0 & 0.0 \\
\hline & Pancreatic fistula & 0 & 0.0 \\
\hline & Intestinal fistula & 1 & 8.3 \\
\hline
\end{tabular}

a result of multi-organ failure and massive pulmonary embolism. Escherichia coli strains were the predominant aetiological factor responsible for wound infection (9/15 cases). Haemorrhagic complications in the period immediately after the procedure were managed by a primary surgical approach. In each case of VARD the procedure was performed once and there was no need to repeat the procedure. Duration of VARD ranged from $85 \mathrm{~min}$ to $145 \mathrm{~min}$. Postsurgical drainage was maintained for 4 to 18 days, depending on the contents being drained and the patient's general condition. In 3 cases drains were replaced after a soft guidewire was placed under $X$-ray supervision (an aqueous contrast agent). Patients left the department when they became independent, but they stayed under the care of a hospital outpatient clinic. Mean hospitalisation duration is presented in a table, depending on the procedure type (Table VII). Cases of early deaths were excluded.

During long-term post-hospital follow-up until December 2012, 18 patients remained under supervision in an outpatient setting. Two deaths were documented. All patients complied with a regimen of dietetic treatment enriched with enzymatic me- 
Table VII. Duration of hospitalisation with regard to different procedures

\begin{tabular}{|c|c|c|}
\hline Type & Procedure & $\begin{array}{c}\text { Total duration of } \\
\text { hospitalisation, mean }\end{array}$ \\
\hline 1 & Laparotomy + necrosectomy + passive drainage (scheduled repeated laparotomies) & 145 \\
\hline 2 & Laparotomy + necrosectomy + active drainage & 85 \\
\hline 3 & Percutaneous drainage + VARD & 66 \\
\hline 4 & Percutaneous drainage & 41 \\
\hline
\end{tabular}

dicinal products. Among 2 patients in whom a large pancreatic cyst was diagnosed, 1 had cystogastrostomy performed, whereas the other 1 received conservative treatment due to too high a risk associated with surgery. In 2 patients due to chronic, severe pain associated with chronic pancreatitis in the period of approximately 18 months since they had left hospital thoracoscopic splanchnicectomy was performed with very good outcomes.

Tables VIII-XII present differences (intervention day, APACHE II Score, hospitalisation duration, CTSI Index, complications) between individual groups (intervention type - "Interv") depending on parameters analysed.

Table VIII. Statistical differences on the day of intervention between individual intervention groups

\begin{tabular}{|lcc|}
\hline $\begin{array}{l}\text { Dunn's multiple } \\
\text { comparison test }\end{array}$ & $\begin{array}{c}\text { Significant? } \\
p<0.05 ?\end{array}$ & Summary \\
\hline Interv 1 vs. Interv 2 & No & NS \\
\hline Interv 1 vs. Interv 3 & Yes & $* * *$ \\
\hline Interv 1 vs. Interv 4 & Yes & $*$ \\
\hline Interv 2 vs. Interv 3 & Yes & $* *$ \\
\hline Interv 2 vs. Interv 4 & No & NS \\
\hline Interv 3 vs. Interv 4 & No & NS \\
\hline
\end{tabular}

Table X. Statistical differences with regard to hospitalisation duration between individual intervention groups

\begin{tabular}{|lcc|}
\hline $\begin{array}{l}\text { Dunn's multiple } \\
\text { comparison test }\end{array}$ & $\begin{array}{c}\text { Significant? } \\
p<0.05 ?\end{array}$ & Summary \\
\hline Interv 1 vs. Interv 2 & No & NS \\
\hline Interv 1 vs. Interv 3 & No & NS \\
\hline Interv 1 vs. Interv 4 & Yes & $*$ \\
\hline Interv 2 vs. Interv 3 & No & NS \\
\hline Interv 2 vs. Interv 4 & Yes & $*$ \\
\hline Interv 3 vs. Interv 4 & No & NS \\
\hline
\end{tabular}

\section{Statistical analysis}

Characteristics of the studied group were described with the following parameters: number $(n)$, mean $(x)$, standard deviation (SD), median (Me), bias, minimum and maximum of a variable. A normal distribution of quantitative variables was assessed based on the results of the Shapiro-Wilk test for normality.

The non-parametric Kruskal-Wallis test was used to compare differences in distributions of studied parameters between independent groups of procedures. Post hoc comparisons were based on Dunn's test. In all analyses below, a significance level of $\alpha=$ $=0.05$ was assumed.

Table IX. Statistical differences in the APACHE II score between individual intervention groups

\begin{tabular}{|lcc|}
\hline $\begin{array}{l}\text { Dunn's multiple } \\
\text { comparison test }\end{array}$ & $\begin{array}{c}\text { Significant? } \\
p<0.05 ?\end{array}$ & Summary \\
\hline Interv 1 vs. Interv 2 & No & NS \\
\hline Interv 1 vs. Interv 3 & Yes & $* *$ \\
\hline Interv 1 vs. Interv 4 & Yes & $* *$ \\
\hline Interv 2 vs. Interv 3 & Yes & $*$ \\
\hline Interv 2 vs. Interv 4 & Yes & $*$ \\
\hline Interv 3 vs. Interv 4 & No & NS \\
\hline
\end{tabular}

Table XI. Statistical differences with regard to the CTSI index between individual intervention groups

\begin{tabular}{|lcc|}
\hline $\begin{array}{l}\text { Dunn's multiple } \\
\text { comparison test }\end{array}$ & $\begin{array}{c}\text { Significant? } \\
p<0.05 ?\end{array}$ & Summary \\
\hline Interv 1 vs. Interv 2 & No & NS \\
\hline Interv 1 vs. Interv 3 & Yes & $* *$ \\
\hline Interv 1 vs. Interv 4 & Yes & $* * *$ \\
\hline Interv 2 vs. Interv 3 & No & NS \\
\hline Interv 2 vs. Interv 4 & Yes & $*$ \\
\hline Interv 3 vs. Interv 4 & No & NS \\
\hline
\end{tabular}


Table XII. Statistical differences with regard to general complications between individual intervention groups

\begin{tabular}{|lcc|}
\hline $\begin{array}{l}\text { Dunn's multiple } \\
\text { comparison test }\end{array}$ & $\begin{array}{c}\text { Significant? } \\
p<0.05 ?\end{array}$ & Summary \\
\hline Interv 1 vs. Interv 2 & No & NS \\
\hline Interv 1 vs. Interv 3 & No & NS \\
\hline Interv 1 vs. Interv 4 & Yes & $* *$ \\
\hline Interv 2 vs. Interv 3 & No & NS \\
\hline Interv 2 vs. Interv 4 & No & NS \\
\hline Interv 3 vs. Interv 4 & No & NS \\
\hline
\end{tabular}

\section{Discussion}

A diagnosis of severe AP is always a great challenge to an interdisciplinary team of physicians. Unfortunately until now no universal management standards have been prepared and so far individualised treatment is recommended for each patient suffering from this disease. There are no controversies only with regard to the initial management strategy applied at the initial disease stage. In such a situation, under intensive care, detailed monitoring of vital signs, fluid therapy, electrolyte supplementation, appropriate nutrition (currently the predominant role of enteral nutrition is emphasised) and prophylaxis of local and generalised complications, especially of an infective nature, are provided [6].

In the case of severe AP surgical (interventional) treatment is allowed when a focus of infected pancreatic necrosis, cyst or abscess has been diagnosed, as well as in selected cases of acute complications associated with this disease, such as gastrointestinal perforation, massive gastrointestinal bleeding or symptoms of compartment syndrome $[7,8]$. It is commonly accepted that a surgical intervention should be delayed as much as possible because when it is performed at an early disease stage it undoubtedly has a negative effect on the outcomes of treatment [9]. The optimum period to perform an intervention starts 3-4 weeks after the first symptoms of disease $[10,11]$. At that time demarcation processes in the necrotic tissue are so advanced that necrosectomy is not associated with such a high risk of complications. It seems to have a critical meaning for minimally invasive procedures as in such cases monitoring of any intraoperative complications may be much more limited. Such complications may for example include intraoperative haemorrhage from the pancreatic tissue that is not completely necrotic. The use of laparoscopy or endoscopy is associated with development of additional complications that are specific for a given method, and sometimes conversion to laparotomy is necessary [12]. However, with better and better management of laparoscopic techniques and appropriate equipment (LigaSure, harmonic knife, local haemostatic agents) it is less and less troublesome to provide for possible intraoperative haemorrhages or other complications.

Video-assisted retroperitoneal debridement used in our department appears to have a vital advantage, in the end, over classic management, as has been reported many times by different research centres in the literature. Only one, small incision used to eliminate necrotic tissues is beneficial to patients as they are not burdened with an additional, major surgical trauma. Moreover, thanks to the application of active post-surgical drainage it is in general not necessary to perform another intervention at a surgical site. It is also possible that the use of percutaneous drainage before videosurgical intervention gives some control of intra-abdominal infection and may improve the efficiency of AP treatment by reducing the reintervention rate. In the comparable material and the method lacking this technique, used by Sileikis et al., the number of surgical reinterventions was significantly higher [13]. The outcomes achieved, although possibly biased with a correlation error, seem to be much better; nonetheless, one cannot forget that when comparing a classic method with a minimally invasive procedure several aspects have to be considered. First of all, treatment methods were not randomised. Unfortunately due to severe patient's condition and a risk associated with using an unascertained method it was not possible to select a technique randomly, and an exceptionally individual, multidisciplinary approach to a patient was required. Additionally, in the initial period the team did not have enough experience with regard to minimally invasive procedures. Moreover, probably in many cases this method was used in patients in a generally better general condition (based on the APACHE II score), and classic, well-known methods were reserved for the most severe cases, with significantly higher dynamics. This fact seems to be confirmed by statistical calculations within this scale, as well as the analysis of the CTSI index in a group of patients in whom classic surgical methods were applied compared to VARD (Tables IX, XI). The highest death rate 
associated with type 1 procedures may therefore be a result of an advanced local stage and severity of resulting complications.

When analysing the course of hospitalisation in patients subject to minimally invasive procedures it can be observed that gradual management of this disease has additional advantages. In some cases even the stage of percutaneous drainage, with a transabdominal or retroperitoneal approach, may be a definitive intervention. It is commonly known that this is a recognised method of treatment of some types of pancreatic necrosis, as well as an excellent method to gain control over intra-abdominal infection [14]. Basic fears associated with VARD including lack of complete control over a surgical field can be dispersed with advanced surgical skills. A careful, blunt approach to the peripancreatic area under ultrasound supervision makes it possible to minimise a potential risk of damage to major vessels or organs. On the other hand, careful removal of necrotic tissue using only a delicate stream of water coming from a suction-flushing device is not associated with too intense haemorrhage. It is extremely vital to select the appropriate time of an intervention when the majority of pancreatic necrotic tissues have become completely demarcated. Consequently it seems that currently open methods should be reserved for the most serious conditions requiring interventions for indications other than infection (compartment syndrome, bleeding, gastrointestinal perforation) that appear at an earlier stage than tissue demarcation. An attempt to control intra-abdominal infection is usually possible the most frequently with the least invasive, percutaneous methods. Constantly gained experience in the use of minimally invasive methods and technological development are the main factors supporting their use in such cases. Compared to the first reports from the mid-2000s the outcomes have become significantly better $[15,16]$. Statistical analyses have not proven that VARD would significantly shorten the hospitalisation duration with regard to classic (open) methods (Table X). Its use is also not associated with a numerically lower number of complications; however, their severity is different, which undoubtedly supports the superiority of this method (Table VI). In this group it was possible to perform minimally invasive procedures in $64.7 \%$ of patients, which confirms previous reports of Horvath et al. [2].

However, medical benefits and economic benefits are not well matched. It turns out that necrosec- tomy in severe cases of AP is associated with significant expenses. They are similar to the ones incurred using classic methods of surgical treatment [17].

Summing up, based on the analysed material, it cannot be concluded whether it is possible to use minimally invasive methods in each case of severe AP. Undoubtedly they can be applied without limits, and are beneficial in cases where necrotic and inflammatory lesions are less advanced. Although a lower rate of general complications has not been proven, the use of such modern methods is associated with less intense complications, and therefore they are easier to treat. In selected cases these methods have superseded traditional methods to treat AP complications and as a result they provided a chance of significantly better therapeutic outcomes in patients suffering from this severe disease.

\section{Conclusions}

When AP and its complications are diagnosed, a suitable method of surgical treatment has to be selected extremely precisely and in an individualised way. Minimally invasive methods used in selected patients provide better outcomes and higher safety superseding classic, open techniques of surgical treatment.

\section{References}

1. Banks PA, Freeman ML. Practice guidelines in acute pancreatitis. Am J Gastroenterol 2006; 101: 2379-400.

2. Horvath K, Freeny P, Escallon J, et al. Safety and efficacy of video-assisted retroperitoneal debridement for infected pancreatic collections: a multicenter, prospective, single-arm phase 2 study. Arch Surg 2010; 145: 817-25

3. Shelat VG, Diddapur RK. Minimally invasive retroperitoneal pancreatic necrosectomy in necrotising pancreatitis. Singapore Med J 2007; 48: 220-3.

4. Besselink MG, van Santvoort HC, Nieuwenhuijs VB, et al. Minimally invasive 'step-up approach' versus maximal necrosectomy in patients with acute necrotising pancreatitis (PANTERtrial): design and rationale of a randomised controlled multicenter trial. BMC Surg 2006; 6: 6.

5. van Santvoort HC, Besselink MG, Horvath KD, et al.; Dutch Acute Pancreatis Study Group. Videoscopic assisted retroperitoneal debridement in infected necrotizing pancreatitis. HPB (Oxford) 2007; 9: 156-9.

6. Yi F, Ge L, Zhao J, et al. Meta-analysis: total parenteral nutrition versus total enteral nutrition in predicted severe acute pancreatitis. Intern Med 2012; 51: 523-30.

7. Deng ZG, Zhou JY, Yin ZY, et al. Continuous regional arterial infusion and laparotomic decompression for severe acute pancre- 
atitis with abdominal compartment syndrome. World J Gastroenterol 2011; 17: 4911-6.

8. Khorsandi M, Beatson K, Dougherty S, et al. Interventional radiology in acute pancreatitis: friend or Foe? J Pancreas (Online) 2012; 13: 91-3.

9. Mier J, Leon E, Castillo A, et al. Early versus late necrosectomy in severe necrotzing pancreatitis. Am J Surg 1997; 173: 71-5.

10. Doctor N, Philip S, Gandhi V, et al. Analysis of the delayed approach to the management of infected pancreatic necrosis. World I Gastroenterol 2011; 17: 366-71.

11. Freeman ML, Werner J, van Santvoort HC, et al. Interventions for necrotizing pancreatitis: summary of a multidisciplinary consensus conference. Pancreas 2012; 41: 1176-94.

12. Bausch D, Wellner U, Kahl S, et al. Minimally invasive operations for acute necrotizing pancreatitis: comparison of minimally invasive retroperitoneal necrosectomy with endoscopic transgastricnecrosectomy. Surgery 2012; 152 (3 Suppl. 1): S128-34.

13. Sileikis A, Beiša V, Beiša A, et al. Minimally invasive retroperitoneal necrosectomy in management of acute necrotizing pancreatitis. Videosurgery Miniinv 2013; 8: 29-35.

14. Carter R. Percutaneous management of necrotizing pancreatitis. HPB (Oxford) 2007; 9: 235-9.

15. Connor S, Alexakis N, Raraty MG, et al. Early and late complications after pancreatic necrosectomy. Surgery 2005; 137: 499505.

16. Castellanos G, Pinero A, Serrano A, et al. Translumbar retroperitoneal endoscopy: an alternative in the follow-up and management of drained infected pancreatic necrosis. Arch Surg 2005; 140: $952-5$

17. Beenen E, Brown L, Connor S. A comparison of the hospital costs of open vs. minimally invasive surgical management of necrotizing pancreatitis. HPB (Oxford) 2011; 13: 178-84.

Received: 8.07.2013, accepted: 14.10.2013. 